\title{
A HOSPITALIDADE SOB A ÓTICA DO ROMEIRO NA ROMARIA AO SANTUÁRIO DE NOSSA SENHORA DE CARAVAGGIO - FARROUPILHA/RS E SEU COROLÁRIO NO CONCEITO DE TURISMO RELIGIOSO
}

HOSPITALITY FROM THE PERSPECTIVE OF PILGRAMS TO THE SANCTUARY OF NOSSA SENHORA DE CARAVAGGIO - FARROUPILHA/RS AND ITS COROLLARY IN THE CONCEPT OF RELIGIOUS TOURISM

LA HOSPITALIDAD, DESDE EL PUNTO DE VISTA DEL ROMERO, EN LA ROMERÍA AL SANTUARIO DE NUESTRA SEÑORA DE CARAVAGGIO - FARROUPILHA/RS Y SU COROLARIO EN EL CONCEPTO DE TURISMO RELIGIOSO

\section{Mônica Schneider}

Mestre em Turismo - Universidade de Caxias do Sul - UCS mschnei1@ucs.br

\section{Marcia Maria Cappellano dos Santos}

Programa de Pós-Graduação em Turismo e Hospitalidade - Mestrado e Doutorado Universidade de Caxias do Sul - Coordenadora mcsantos@ucs.br Data de Submissão: 02/12/2014 Data de Aprovação: 01/03/2015

Resumo: Este trabalho volta-se para relações de hospitalidade na romaria ao Santuário de Nossa Senhora de Caravaggio - Farroupilha/RS sob a ótica do romeiro. Prática religiosa que perdura por mais de um século, mobiliza anualmente milhares de pessoas, abarcando uma ampla estrutura receptiva. Assim, num contexto teórico para o qual confluem conceitos de espiritualidade e religiosidade, turismo religioso e hospitalidade, tem-se como objetivo identificar, analisar e interpretar, 
via discurso, sinalizadores de relações de hospitalidade sob a perspectiva do romeiro. A pesquisa, prioritariamente qualitativa, compreendeu entrevistas semiestruturadas com participantes da romaria de 2012. Mediante técnicas de análise de conteúdo e de marcas enunciativas, foram categorizados fragmentos das respostas dos entrevistados. Os sinalizadores discursivos apontam, relativamente, à hospitalidade para a predominância de aspectos vinculados ao planejamento e à organização socioadministrativa da romaria, seguidos das relações sócio-humanas que nela se efetivam. Esses sinalizadores foram ainda analisados estabelecendo-se elos com as manifestações dos sujeitos sobre as motivações para a ida a Caravaggio, a experiência de participação no evento, assim como os destaques que seriam dados sobre a romaria a um eventual futuro romeiro - o que possibilitou, com o apoio de subsídios empíricos, aportar outro olhar teórico sobre os conceitos de peregrinação/ romaria e de turismo religioso.

Palavras-chave: Turismo religioso. Hospitalidade/Acolhimento. Romaria ao Santuário de Nossa Senhora de Caravaggio - Farroupilha/RS.

Abstract: This work analyzes the relations between hospitality in the Pilgrimage to the Sanctuary of Nossa Senhora de Caravaggio - Farroupilha/RS from the pilgrim's perspective. This pilgrimage is a religious practice that has continued for more than a century and attracts thousands of people each year, comprising a broad hospitality structure. Thus, in a theoretical context in which the concepts of spirituality and religiosity, religious tourism, and hospitality converge, this work aims to identify, analyze and interpret, by means of discourse, indicators of hospitality relations from the pilgrims' perspective. This mainly qualitative study included semi-structured interviews with participants of the 2012 Pilgrimage. Using techniques of content analysis and enunciative signs, fragments of the interviewees' responses were categorized. The discourse signs indicate, in relation to hospitality, a predominance of aspects linked to planning and socio-administrative organization of the Pilgrimage, followed by the socio-human relations in which these occur. These signs were also analyzed establishing links with the subjects' responses regarding their reasons for going to Caravaggio, the experience of participating, and the things they would highlighted about the event, for any future pilgrimage. Supported by empirical resources, the data gathered enabled a different theoretical view of the concepts of pilgrimage and religious tourism.

Key-words: Religious Tourism. Hospitality/Welcoming. Pilgrimage to the Sanctuary of Nossa Senhora de Caravaggio - Farroupilha/RS.

Resumen: Este trabajo involucra las relaciones de hospitalidad en la Romería al Santuario de Nuestra Señora de Caravaggio - Farroupilha/RS, desde el punto de vista del romero. Práctica religiosa que perdura desde hace más de un siglo, moviliza anualmente miles de personas, abarcando una amplia estructura receptiva. Así, en un contexto teórico hacia el cual confluyen conceptos de espiritualidad y religiosidad, turismo religioso y hospitalidad, se plantea como objetivo identificar, analizar e interpretar, vía discurso, los señalizadores de las relaciones de hospitalidad bajo la perspectiva del romero. La investigación, prioritariamente cualitativa, ha comprendido entrevistas semiestructuradas con participantes de la Romería del año 2012. Mediante técnicas de análisis de contenido y de marcas enunciativas, se han categorizado fragmentos de las respuestas de los entrevistados. Los señalizadores discursivos apuntan, respectivamente, a la hospitalidad, para la predominancia de aspectos vinculados al planeamiento y a la organización socio administrativa de la Romería, seguidos de las relaciones socio-humanas que en ella se han efectuado. Esos señalizadores fueron analizados también estableciéndose conexiones con las manifestaciones de los sujetos sobre las motivaciones para la ida a Caravaggio, la experiencia de participación en el evento, así como los destaques que serían dados sobre la Romería a un eventual futuro romero - lo que ha posibilitado, con el apoyo de subsidios empíricos, aportar otro enfoque teórico sobre los conceptos de peregrinación/romería y de turismo religioso. 
Palabras clave: Turismo Religioso. Hospitalidad/Acogimiento. Romería al Santuario de Nuestra Señora de Caravaggio - Farroupilha/RS.

\section{CONSIDERAÇÕES INTRODUTÓRIAS}

s peregrinações e as romarias têm sido objeto de estudos sob
diferentes perspectivas, dentre as quais a do turismo religioso e da
hospitalidade. É nesse contexto que se situa o presente trabalho, trazendo à reflexão relações de hospitalidade na Romaria ao Santuário de Nossa Senhora de Caravaggio (RNSC) - Farroupilha/RS, sob a ótica do romeiro.

ARNSC caracteriza-se como um dos principais eventos, não só de Farroupilha/ RS, mas também da região e do estado. Iniciada por algumas famílias no ano de 1879, a RNSC, hoje, atrai mais de 200 mil romeiros ao pequeno distrito de Farroupilha, no final do mês de maio (especificamente no dia 26 de maio e no sábado e no domingo mais próximos a essa data). Ao longo dos anos, a devoção a Nossa Senhora de Caravaggio foi aumentando, e essa prática religiosa consolidou-se, atraindo um número cada vez mais expressivo de pessoas. Ela abarca também uma ampla estrutura receptiva, promovendo interações de cunho pessoal, social e institucional. Nesse retrospecto, ressalta-se a $133^{a}$ RNSC, ocasião em que foram coletados os dados para esta pesquisa, que se realizou nos dias 26 e 27 de maio de 2012. Nessa Romaria, estiveram presentes cerca de 230 mil pessoas (ROMARIA, 2012, p. 5).

Um destaque particular pode ser dado ao fato de esta pesquisa ter se originado a partir de outra, realizada durante a Graduação em Turismo (no ano de 2010), na qual se buscou analisar o entendimento e as práticas de hospitalidade na Romaria sob a ótica do sujeito primariamente acolhedor, isto é, o próprio Santuário de Nossa Senhora de Caravaggio (representado pelo seu Reitor), o poder público de Farroupilha (representado a Secretaria de Desenvolvimento Econômico e Turismo do município) e empreendimentos privados localizados no entorno do Santuário (representados por um hotel e dois restaurantes).

A proposição da presente investigação, portanto, situa-se na perspectiva de dar continuidade à pesquisa realizada em 2010, conforme mencionado, trazendo 
à reflexão a ótica do sujeito primariamente acolhido - o romeiro que se dirige ao Santuário de Nossa Senhora de Caravaggio - no que se refere a relações de hospitalidade na Romaria. Nesse sentido, o presente trabalho propõe, como objetivo geral, identificar e analisar relações de hospitalidade na RNSC, sob a ótica do romeiro, num contexto teórico para o qual confluem conceitos de espiritualidade e religiosidade, turismo, turismo religioso e hospitalidade. Especificamente, a pesquisa objetiva identificar, analisar e interpretar, via discurso, à luz do marco teórico de referência, sinalizadores das relações de hospitalidade vistas sob a perspectiva do romeiro. Complementarmente, propõe uma reflexão sobre a denominação da romaria como modalidade de turismo religioso.

\section{DESENHANDO UM PERCURSO REFLEXIVO}

Ao buscar desenhar um percurso reflexivo no sentido de construir um quadro teórico para pautar análises pretendidas, configuram-se três núcleos conceituais que se entrelaçam. Primeiramente, partindo-se do entendimento de romaria como uma prática religiosa e, no presente caso, de uma romaria a um santuário católico que envolve devoção a Maria, mostra-se relevante trazer à reflexão conceitos como os de religião, espiritualidade e religiosidade. Por outro lado, a romaria compreende deslocamento em cuja motivação estaria uma devoção, ou a busca de experienciar uma relação com o sagrado. Nisso se delineariam aproximações com conceitos de turismo centrados no deslocamento e, assim, aproximações com o que se tem denominado de turismo religioso. A esse segundo núcleo de vínculos com o turismo vem somar-se um terceiro, cujo foco recai de modo especial sobre relações interpessoais envolvendo os romeiros e as pessoas direta ou indiretamente afetas à estrutura receptiva e de organização. Essas interações estão envoltas por desejos, expectativas, demandas, elementos presentes em relações de acolhimento/hospitalidade (termos aqui tomados como equivalentes), em sua forma singular ou coletiva. Esse universo conceitual é abordado na sequência. 


\section{ESPIRITUALIDADE E RELIGIOSIDADE: \\ RELIGIÃO COMO ITINERÁRIO}

A palavra "religião" origina-se da palavra latina religio, que significa religar, estando relacionada a tradições espirituais que sustentam ritos e celebrações presentes na cultura e na história. Salgueiro e Goldim (2007) acrescentam ainda que religar compreende o ato de ligar, de estabelecer uma ligação dos seres entre si, religando-os a Deus ou a uma força poderosa. A religião também poderia ser entendida como "[...] o conjunto de doutrinas e práticas institucionalizadas, cujo objeto e objetivo é fazer a ponte de ligação entre o sagrado e o profano, o caminho de reaproximação entre criatura e criador, o Homem e Deus" (MANOEL, 2008, p. 19).

Durkheim (1996, p. 32) propõe a seguinte definição de religião: "uma religião é um sistema solidário de crenças e práticas relativas a coisas sagradas, isto é, separadas, proibidas, crenças e práticas que reúnem numa mesma comunidade moral, chamada igreja, todos aqueles que a ela aderem". Outros estudos há sobre religião que se centram na oposição "sagrado/profano", como o faz Mircea Eliade, cuja obra $\mathbf{O}$ sagrado e o profano: a essência das religiões é comumente tomada como referência. Eliade (1992) busca apresentar o fenômeno do sagrado em sua totalidade e complexidade, bem como as dimensões específicas da experiência religiosa, salientando suas diferenças com a experiência profana e descrevendo as modalidades do sagrado. Para ele, a religião "[...] não implica necessariamente a crença em Deus, deuses ou fantasmas, mas [...] se refere à experiência do sagrado e, consequentemente, se encontra relacionada com as idéias de ser, sentido e verdade" (ELIADE, 1989, p. 9, grifo do autor). Ressaltando que o sagrado define-se, primeiramente, por oposição ao profano, afirma que grande parte das definições do fenômeno religioso estabelecem uma oposição entre o sagrado/a vida religiosa e o profano/a vida secular. Complementando essa ideia, refere que o sagrado e o profano constituem duas modalidades de ser no Mundo, duas situações existenciais assumidas pelo homem ao longo de sua história (ELIADE, 1992; 1998). 
Aproximações das categorias Religiosidade e Espiritualidade à religião são mencionadas por Manoel (2008, p. 19) e por Balbinot (2011, p. 18), para os quais, respectivamente, as igrejas constituem-se, por vezes, em "[...] canal de manifestações da religiosidade", e "O início de qualquer religião nasce de uma espiritualidade". Bettega (2009) refere que a religiosidade se encontra diretamente ligada a um jeito específico de manifestar a ligação com o transcendente, expressando características próprias de cada religião, sendo, portanto, uma das formas de vivenciar a espiritualidade. Entende assim que, embora existam relações entre espiritualidade e religiosidade, esses fenômenos não podem ser confundidos nem tratados de forma semelhante. Para o autor, a espiritualidade é mais ampla e até independente desta ou daquela religião. Ela consiste na dimensão humana da busca da transcendência.

Pode-se dizer, desse modo, que, vinculada à experiência - e não a dogmas, doutrinas, ritos -, é a espiritualidade que produz no ser humano uma mudança interior, revelando-se na capacidade de diálogo consigo mesmo, na escuta do outro e no cuidado com o outro, traduzindo-se em amor, em sensibilidade (BOFF, 2006). Contudo, a prática da romaria, além de possíveis elos estabelecidos com o universo da espiritualidade, da religiosidade, ou mesmo da religião, conduz à configuração de outros vínculos, dentre os quais aqueles que a inseririam também no quadro das práticas turísticas, ou, mais especificamente, das práticas de turismo religioso. Com o intuito, pois, de buscar delinear mais claramente essas relações, são aqui retomados, numa perspectiva ora diacrônica, ora sincrônica, os conceitos de turismo, turismo religioso, aportando, inclusive, o pensamento da Igreja Católica expresso em documentos da Pastoral do Turismo.

\section{TURISMO E TURISMO RELIGIOSO}

Em sendo o turismo entendido como um fenômeno de caráter complexo e multi-inter-transdisciplinar, ele tem sido, ao longo do tempo, objeto de estudo sob diferentes abordagens, englobando elementos como objetivo, motivação e duração da viagem, distância percorrida, entre outros aspectos, levando assim à construção de diversas definições. Dentre essas, a definição operacional adotada para o presente estudo compreende uma abordagem da dimensão humana 
do turismo sob as lentes da Psicologia, tendo por suposto teórico de base o conceito de pulsão epistemofílica, proposto por Freud. Nessa abordagem, Perazzolo, Santos e Pereira (2013a) compreendem o humano como valor essencial fundante do turismo, sem, contudo, desconsiderar outras perspectivas que o envolvem. Sob essa ótica, as pesquisadoras buscam trazer à discussão teórica o elemento que poderia ser considerado propulsor do turismo: o desejo, que emerge de diferentes formas na condição de uma metáfora do objeto original inacessível. Nessa direção, entendem que a prática turística é motivada pelo impulso/vontade de conhecer/ver/viver o novo, o outro na sua forma mais intrínseca. Assim, a prática turística não seria resultante, primariamente, do efeito e da persuasão das ações de marketing e vendas e nem da influência de estratégias econômicas e comerciais, mas sim da "[...] motivação primeira à busca do 'novo' [que] estaria sustentada na demanda da busca do prazer em 'outro lugar', onde o objeto original não pode ser identificado" (PERAZZOLO; SANTOS; PEREIRA, 2013a, p. 142, tradução nossa). Esse processo de conhecer é então particularmente potencializado nas relações que se estabelecem no acolhimento. Dito de outro modo, é pela via do acolhimento, potencializada pela interação, que a experiência turística pode tornar-se fonte de saber (PERAZZOLO; SANTOS; PEREIRA, 2013b).

Ao ter em conta, portanto, essa breve incursão teórica sobre o conceito de turismo, a qual destaca o viés que põe em foco sua dimensão humana, parece, em princípio, emergir possibilidades de aproximação da participação em romarias, de um lado, com aspectos, como impulso/vontade de conhecer, busca da experiência humana; de outro, com o universo da religiosidade e da espiritualidade (busca do transcendente). Ambas as aproximações, com tonalizações interpretativas diferentes são, de algum modo, abordadas por aqueles cujos estudos se voltam para o que denominam "turismo religioso".

O turismo religioso, assim como o próprio turismo, apresenta-se como um fenômeno múltiplo, de caráter complexo, abrangendo diferentes significados e motivações e podendo ser analisado e compreendido por meio de abordagens diversas. Historicamente, é possível identificar a existência de interfaces entre fé/ religião e deslocamento/turismo. Pode-se dizer que a história da humanidade foi, em parte, acompanhada pelo fenômeno religioso, representado pela fé, 
pela devoção e pelas peregrinações. Também, em torno desse fenômeno, observa-se a necessidade de uma estrutura de hospitalidade, para atender aos que dele participavam. Acompanhando esse processo histórico das peregrinações, muitos estudiosos perguntam-se: "[...] por que denominamos hoje esse fenômeno milenar de 'turismo religioso'? Como é possível olhar para essa deambulação religiosa e penitencial, e entendê-la como um fenômeno turístico?" (ABUMANSSUR, 2003, p. 54, grifo do autor). Essas perguntas poderiam ser respondidas de diversas formas, e, segundo esse autor, uma das possíveis respostas estaria centrada no princípio de que o turismo religioso é um fenômeno moderno.

Carneiro (2004, p. 72), fazendo alusão aos estudos de Dean MacCannell, cita que, "[...] o turismo moderno pode ser visto como uma continuação das peregrinações tradicionais, carregando sentidos e valores que em outros momentos estiveram condensados nesta experiência religiosa", o que se aproxima aos dizeres de Oliveira (2004, p. 13): "O turismo religioso tem sua origem no exercício contemporâneo da peregrinação". Sob esse prisma, ainda de acordo com o autor, a peregrinação, como uma forma de expressão de fé, começou a ser tratada recentemente como turismo religioso, representando uma nova forma de percepção para um fenômeno milenar.

Para o Padre Carlos Chiquim (s.d.), Secretário Executivo da CNBB Regional Sul II, a adjetivação "religioso" atribuída ao turismo envolve uma amplitude espiritual e metafísica, de sorte que se trata de um fazer turístico capaz de manifestar algum dado de religiosidade e, por essa razão, as peregrinações e as romarias aos lugares sagrados, em momentos sagrados, podem ser chamadas de turismo religioso. Entretanto, também alerta para a possibilidade de o turismo religioso assumir um caráter multifuncional referente a duas dimensões possíveis do aspecto motivacional: aquela que dá lugar ao visitante peregrino puro, cuja motivação é unicamente religiosa, e sua jornada, unifuncional (motivado por sua fé, ele vai ao encontro do local sagrado para cumprir um voto, pagar uma promessa, ou, apenas, manifestar sua adesão a uma determinada fé, movido por uma mística - o que independe da crença religiosa); e aquela que daria lugar ao visitante denominado simplesmente "turista", ao ser ampliado o leque de motivações na jornada (jornada multifuncional). Poder-se-ia aqui falar em um 
peregrino-turista ou em um peregrino com momentos de turista, momentos esses obtidos com ou sem auxílio/promoção de organizadores, dedicados, por exemplo, a visitas culturais e ao repouso.

Assim como para Beni (2007), também para Oliveira (2004), um peregrino pode ser considerado um turista religioso, na medida em que atualiza a prática da peregrinação, adaptando sua viagem (total ou parcialmente) às características do processo turístico. Destacando o caráter religioso dessa modalidade de turismo, Dias e Silveira (2003) ressaltam entre os eventos de caráter religioso, romarias, peregrinações e visitação a espaços, festas, espetáculos e atividades religiosas.

Para uma abordagem-síntese das considerações até aqui trazidas a respeito do turismo religioso, poder-se-ia assim dizer que, no contexto turístico-religioso, as fronteiras entre os campos sociais "turismo" e "religião" se mostram porosas, fluidas conforme a perspectiva a partir da qual são focalizados. Desse modo, a considerar esses referentes, o turismo religioso conjugaria elementos religiosos e turísticos, colocando-os em permanente diálogo, sem que haja o predomínio de um sobre o outro (CARNEIRO, 2004). O turismo religioso, como fenômeno complexo, abrangeria e integraria muitas formas de vivências, podendo reunir, ao mesmo tempo, em seus espaços, experiências diversas. Ao se falar em turismo religioso, a religiosidade passaria a ser permeada pelo fazer turístico, e o fazer turístico, pela religiosidade. Todavia, pode-se identificar que, no quadro do turismo religioso, ganham ainda destaque as peregrinações e as romarias. $E$, especialmente, por este trabalho focalizar as relações de hospitalidade em uma romaria, esta, assim como as peregrinações, serão tratadas no próximo tópico.

\section{PEREGRINAÇÕES E ROMARIAS}

Assim como o turismo religioso, as peregrinações e as romarias suscitam uma gama de discussões, que se estendem desde a compreensão do significado dessas práticas, até as relações que estas estabelecem com o turismo religioso. Desse modo, as formas de entendimento a respeito das peregrinações e das romarias também são múltiplas e diversificadas, envolvendo várias perspectivas de interpretação. 
Especificamente, o termo "peregrinação", como construção social, abarca uma infinidadede experiências, tantohistóricas quanto atuais, de deslocamentos motivados pela devoção e pelo culto (STEIL, 2003). Da mesma maneira, pode-se dizer que o ato de peregrinar é, de certa forma, uma herança das origens nômades dos grupos humanos, sendo que a peregrinação realiza-se com o propósito de buscar algo mais significativo (OLVEIRA, 2004). E, mesmo que se apresentem sob uma diversidade de motivações, as peregrinações, em sua essência, podem ser consideradas um fenômeno ligado à natureza do ser humano (RIBEIRO, 2003). Seguindo essa mesma perspectiva, Brustolin (2007, p. 234) destaca, como condição real do ser humano, o estar a caminho (homo viator), sendo esse caminhar uma categoria espiritual, uma forma de a pessoa encontrar-se consigo mesma: "Partir significa romper com a inércia habitual, é dispor-se a avançar, crescer e conhecer o novo". Nessa linha reflexiva, De Fiores e Meo (1995) referem que a peregrinação faz parte da essência da igreja e da sua missão, sendo que a peregrinação não está presente apenas no cristianismo ocidental, mas sim representa um fenômeno universal.

Diferentemente da peregrinação, que compreende longos deslocamentos para santuários importantes, o termo "romaria", segundo Nolan e Nolan (1989), específico das línguas portuguesa e espanhola, está relacionado a deslocamentos curtos envolvendo comunidades e combinando aspectos festivos e devocionais. Então, a romaria tem como característica deslocamentos menores e, a peregrinação, deslocamentos que envolvem maiores distâncias. Historicamente, as romarias remontam às peregrinações cristãs a Roma, lugar de martírio dos apóstolos Pedro e Paulo. De "Roma" teria originado a palavra "romaria" (peregrinação a Roma) (CRISPIM, 2002).

As romarias, para Duarte (2010, p. 3) continuam sendo uma das maiores manifestações públicas da fé católica, reunindo múltiplas formas de experiências, alimentando os sentidos do rezar, do caminhar, do fazer/pagar promessas, e cujos rituais simbólicos, inseridos em contextos históricos e geográficos marcados pela diversidade, "[...] envolvem uma teia de produções de ritos que apresentam vários pontos comuns: o costume de caminhar, o deslocar-se [...], a divulgação dos milagres, a exposição das graças alcançadas, a solicitação de novos pedidos, os exageros dos sacrifícios físicos". Pensar as romarias poderia ser realizado, como refere Cordeiro (2011), a partir da matriz interpretativa das peregrinações, pois, independentemente de características específicas que 
podem ser atribuídas a uma ou outra prática, no universo de ambas está a vivência de um ato religioso de imersão no sagrado, recobrindo movimentos físicos, espirituais e temporais.

Há também perspectivas teóricas sob as quais o turismo religioso poderia ser diferenciado da peregrinação ou da romaria, sendo aquele caracterizado pela externalidade do olhar e estas, pela internalidade da imersão no sagrado, sem que nisso interfira o critério da utilização da estrutura turística. Na opinião de Steil (2003), peregrinação, romaria e turismo religioso, embora muitas vezes tenham sido consideradas práticas equivalentes, apresentam diferenças, quando observadas nos contextos religioso e social em que se inserem. Desse modo, para diferenciar o turismo da peregrinação ou da romaria, Steil (2003, p. 35) entende que:

[...] o ponto fulcral reside no grau de imersão e de externalidade que cada uma dessas experiências pode proporcionar. Enquanto as peregrinações e romarias tendem a ser vivenciadas como um ato religioso de imersão no sagrado, o turismo, mesmo quando adjetivado como religioso, caracteriza-se por uma externalidade do olhar, fundamental para que um evento possa ser considerado como turístico (AMIROU, 1995). Ou seja, se a experiência da peregrinação e romaria está centrada na participação [...], o turismo está mais associado ao espetáculo.

Em certa medida, aqui também poderia ser referido Pastor (2009), em cuja definição de turismo religioso encontra-se a busca de conhecimento de diversos enclaves da manifestação religiosa, aproximando-se de uma forma de turismo cultural, enquanto que a peregrinação se define como viagem de caráter religioso, na qual a motivação prioritária são os rituais e o culto. "No caso do turismo religioso, a orientação cultural se dirige até as manifestações externas da religiosidade e pode não ter uma vinculação subjetiva com o fato religioso" - ressalta o autor (2009, p. 140, tradução nossa).

\section{TURISMO RELIGIOSO E HOSPITALIDADE SOB A ÓTICA DA IGREJA CATÓLICA}

Uma abordagem acerca do turismo religioso remete naturalmente à Pastoral do Turismo, que promove o acolhimento e o apoio aos turistas, voltando seu 
olhar também para agentes de viagens, guias de turismo, residentes dos lugares que recebem turistas e todos os envolvidos nessa atividade (CNBB, 2009). Sob a perspectiva do acolhimento, a Igreja tem presente que "A hospitalidade era considerada pelos primeiros cristãos como um dever fundamental e uma das expressões mais autênticas da caridade. A pessoa acolhida se sente bem; as portas que lhe são abertas a estimulam a abrir as portas de seu coração" (CNBB, 2009, p. 237). A hospitalidade constitui-se, assim, em um dos principais núcleos da Pastoral do Turismo e representa também uma das atitudes fundamentais da comunidade cristã (CNBB, 2009).

Na concepção da Igreja, o ser humano possui, como necessidades essenciais, o viajar, o encontrar-se com outros, o conhecer lugares, o estar em contato com outras culturas e, em grande parte, é em virtude dessas necessidades que o turismo se desenvolve. A Igreja entende que é próprio da natureza do ser humano deslocar-se para conhecer outros lugares, não estando preso a um determinado lugar. O ser humano é inquieto por natureza, sendo essa inquietude "própria da condição de Homo viator" (CNBB, 2009, p. 86), este caracterizado como "[...] um viandante que tem sede de novos horizontes e fome de paz e de justiça, investigador da verdade, desejoso de amor, aberto ao absoluto e ao infinito" (CNBB, 2009, p. 108). Assim, "Somos eternos viajantes, à procura do novo, do desconhecido, do belo" (CNBB, 2009, p. 9). As pessoas movem-se, na busca de satisfazer seus desejos e de viver novas experiências (CNBB, 2009).

Inserida no âmbito do turismo que seria caracterizado como religioso, encontra-se a Pastoral das Peregrinações, uma vez que os santuários, além de meta de peregrinação de cristãos, tornaram-se também, na atualidade, o destino de um grande número de turistas, assim como as catedrais, os mosteiros e os antigos caminhos de peregrinação, os quais exercem grande atração sobre o ser humano. Dessa forma, nas peregrinações, não só se realizam visitas a lugares religiosos, mas também são previstos, por organizadores ou por peregrinos, momentos dedicados às visitas culturais e ao repouso.

Cabe lembrar que, para Krieger (2007), peregrinos e turistas apresentam posições e atitudes distintas, sendo que, sob esse entendimento, um peregrino não é um simples turista. Por conseguinte, o incentivo à e o cuidado com a visitação de lugares sagrados é tão importante quanto a preparação daqueles 
que realizarão a peregrinação. "Caso contrário, esvazia-se a experiência e transforma-se o peregrino em um simples turista" (KRIEGER, 2007, p. 6). A Igreja, do mesmo modo, preocupa-se com a acolhida daqueles que visitam os santuários. Nesse sentido, "Se for oferecido um acolhimento adequado [...] [aos] visitantes, eles poderão fazer uma profunda experiência de fé" (KRIEGER, 2007, p. 5-6). Portanto, a Igreja vê o turismo como uma oportunidade de evangelização e, se o turista receber uma acolhida adequada e uma preparação para a peregrinação, ele poderá converter-se em peregrino e vivenciar uma verdadeira experiência religiosa. Senão, essa experiência será somente turística, não apresentando o envolvimento religioso almejado.

A hospitalidade, fenômeno sob o qual a Igreja também confere destaque, ressaltando a importância, em diversos aspectos, da acolhida aos turistas, será, neste momento, trazida mais pontualmente à reflexão.

\section{HOSPITALIDADE}

A hospitalidade, considerada um dos núcleos conceituais a serem chamados na análise das relações de hospitalidade na RNSC, surge como campo científico emergente e complexo. Ela remonta a vários séculos e civilizações, associandose a aspectos sociais e religiosos (BUENO, 2003). Portanto, está presente no pensamento mítico, religioso e científico de diversos povos, como um dever, uma virtude e um direito (CAMARGO, 2002). Apesar de grande parte das definições associarem a hospitalidade com a abertura para o acolhimento (BUENO, 2003), ela pode ser abordada de diversos ângulos, de acordo com as suas várias articulações. Assim, a hospitalidade, com a característica de ser multifacetada, requer abordagens interdisciplinares e a contribuição de diversas áreas do conhecimento (CRUZ, 2002).

Face a tantos conceitos que norteiam as noções a respeito da hospitalidade, procurar-se-á dar destaque a alguns deles, apresentando diferentes abordagens e enfoques, buscando interpretá-los em suas diversas relações. Entre as múltiplas definições de hospitalidade, os pontos em comum que se pode encontrar com mais frequência dizem respeito ao acolhimento, ao bem-receber e ao atender as expectativas e satisfazer os desejos das pessoas. 
Gotman (2001) conceitua a hospitalidade como um processo de agregação do outro à comunidade, sendo a inospitalidade o processo inverso. De igual forma, Baptista (2002, p. 157) define hospitalidade como: "[...] um modo privilegiado de encontro interpessoal marcado pela atitude do acolhimento em relação ao outro", representando a disponibilidade da consciência para acolher a realidade fora de si. Gidra e Dias (2004) também enfatizam a noção de hospitalidade como fenômeno caracterizado pela relação entre dois protagonistas. Seguindo a mesma linha de pensamento, Dencker (2003, p. 146) defende a ideia de que a hospitalidade é uma "[...] forma de receber o outro, de exercitar a alteridade, de conviver com as diferenças dentro de parâmetros de respeito, tolerância e reciprocidade".

Os conceitos citados exemplificam os diferentes enfoques que podem ser encontrados em estudos sobre hospitalidade e revelam que, atualmente, esse fenômeno associa-se a aspectos mais amplos, englobando muito mais do que o hospedar e o alimentar. Nessa perspectiva, a abordagem adotada como de referência para este trabalho, de base psicossociológica, considera a hospitalidade como um dos eixos fundantes do turismo, na medida em que se parte do princípio de que é a dimensão humana que caracteriza o valor essencial do turismo (PERAZZOLO; SANTOS; PEREIRA, 2013a). Nesse sentido, na base do acolhimento/hospitalidade "[...] estaria a disposição de acolher o outro na sua singularidade, de respeitá-lo, de conhecê-lo, sem imposições a priori, de forma 'incondicional' [...]". Isso porque "[...] em impondo seu espaço, suas normas, sua cultura, o acolhedor estaria acolhendo apenas, a si mesmo, na direção de seu próprio prazer" (PERAZZOLO; SANTOS; PEREIRA, 2013a, p. 145, tradução nossa).

Dessa forma, ainda segundo as autoras, pode ser concebido como fenômeno que se instala no espaço constituído entre o sujeito (na sua forma singular e coletiva) que deseja acolher e o sujeito que deseja ser acolhido. $O$ acolhimento, então, é compreendido como fenômeno relacional (envolvendo troca e negociação entre os sujeitos em interação) e não como um comportamento ou um simples ato humano. Portanto, de acordo com as pesquisadoras, hospitalidade: 
[...] não seria apenas o ato de acolher supondo um único vértice do processo. Tampouco seria a expressão do desejo de um ou de outro sujeito situado em qualquer um dos polos da interação, e, também, não seria apenas o produto da relação direta que estabelecem. Hospitalidade ou acolhimento seria, nessa perspectiva, uma área constituída na intersecção resultante do encontro dinâmico de demandas distintas, com origem necessariamente, numa perspectiva subjetiva do desejo, orbitado por eventos circunstanciais. [Sob esse ponto de vista, para que haja acolhimento, é preciso que se estabeleça uma troca entre os sujeitos envolvidos nessa interação, ou seja, ambos os sujeitos têm que se ajustar dinamicamente na interação de suas necessidades]. (PERAZZOLO; SANTOS; PEREIRA, 2013a, p. 146, tradução nossa).

A hospitalidade encontra-se na relação com o outro e é marcada pela percepção mútua dos desejos que são acolhidos, traduzidos, compreendidos e transformados em uma nova mensagem dotada de novos significados, estabelecendo-se, assim, um ciclo interativo que permite a geração de novos saberes. "Nesse processo, acolhedor e acolhido se distanciam progressivamente de demandas autocentradas e de verdades a priori, ou seja, de seus desejos e convicções prévias, voltando-se um para o outro, abertos a novos saberes" (SANTOS; PERAZZOLO; PEREIRA, 2012, p. 6).

Acrescentando outras perspectivas ao estudo da hospitalidade, Santos, Perazzolo e Pereira (2012) enfatizam que no âmbito das relações de acolhimento encontram-se experiências vividas por sujeitos primariamente acolhidos e primariamente acolhedores. Na proposição dessa ideia, as pesquisadoras procuram destacar posições iniciais para o sujeito acolhedor e para o acolhido, os quais, a partir de um processo de alternância relacional, ou seja, da instauração do fenômeno da hospitalidade, transformam-se, ao mesmo tempo, em sujeitos que acolhem e são acolhidos. Sob esse entendimento,

O turista, assim, está, primariamente, na posição de quem se desloca em busca de conhecer (o conhecer pode adquirir diferentes formas, como as de "adquirir" o novo, "ver" o novo, "viver" o novo). O acolhedor, por outro lado, está, primariamente, na posição de quem recebe o visitante. No entanto, destaque-se que se trata de uma condição primária, pois, se o acolhimento ocorre, acolhedor e acolhido se alternam o tempo todo. Em síntese, embora nem sempre alinhado no tempo e no espaço, é o processo de interação, constituído na forma de trocas que envolvem moeda, produtos, 
No caso do presente estudo, o pensar a hospitalidade na Romaria de Caravaggio, além da cultura religiosa ali instituída, que carrega marcas de valores, saberes e conhecimentos produzidos e apropriados, inclui também serviços disponibilizados e processos de gestão. Sendo assim, há que se pensar hospitalidade numa perspectiva coletiva de acolhimento, sendo, por isso, o conceito de Corpo Coletivo Acolhedor, proposto por Santos, Perazzolo e Pereira (2012) incluído no conjunto das reflexões.

O conceito de Corpo Coletivo Acolhedor é proposto pelas autoras com base no entendimento de que a relação de hospitalidade compreende sujeitos tanto na perspectiva singular quanto na coletiva. Parte-se do entendimento de que a estruturação de um corpo social, de um grupo, uma comunidade, abarcando elementos tangíveis e intangíveis, se dá pela interligação de, pelo menos, três vértices: trocas/serviços (disponibilizados no âmbito das relações internas/ externas); capital cultural (conhecimento gerado, compartilhado e transmitido pelo grupo/comunidade); organismo gestor (de natureza operacional, pública e privada). E é no espaço dessa triangulação que se organizam e se desenvolvem o fenômeno do acolhimento e as práticas de hospitalidade, bem como a relação do romeiro com o Corpo Coletivo que o acolhe. Analisar a hospitalidade na Romaria sob a ótica desse romeiro parece, pois, apontar para essa relação como um elemento importante a ser considerado, juntamente com os outros aportes teóricos aqui trazidos como referentes analíticos.

\section{TRILHANDO OS CAMINHOS METODOLÓGICOS}

De natureza predominantemente qualitativa e com uma abordagem hermenêutica, a pesquisa apoiou-se em procedimentos/técnicas da Análise de Conteúdo, segundo Bardin (2000) e, complementarmente, da Análise Enunciativa, na esteira da abordagem proposta por Bakhtin (1997). A coleta de dados, por recorte metodológico, ocorreu nos espaços territoriais afetos diretamente à $133^{a}$ RNSC, que se realizou nos dias 26 e 27 de maio de 2012. $\mathrm{Na}$ oportunidade, foi aplicado o instrumento elaborado para a coleta de 
dados, o qual consistiu em um questionário semiestruturado, que orientou as entrevistas semipadronizadas. Em se tratando de uma pesquisa de caráter predominantemente qualitativo, realizaram-se 70 entrevistas, cujos sujeitos foram selecionados aleatoriamente, procurando-se, no entanto, atentar a alguns critérios, como: não entrevistar romeiros envolvidos em ritos religiosos ou fazendo refeições; distribuir a realização das entrevistas em diferentes horários e espaços no entorno do Santuário. Os eixos condutores das entrevistas e, posteriormente, da análise dos dados, foram: Perfil do Romeiro (gênero, procedência, faixa etária, número de participações na Romaria, forma de locomoção); Manifestações/Destaques sobre Acolhimento/Hospitalidade na Romaria; Motivações para a Ida a Caravaggio; Experiência de Participação no Evento; Destaques sobre a Romaria a um Eventual Futuro Romeiro.

\section{LANÇANDO O OLHAR SOBRE OS FRAGMENTOS DISCURSIVOS}

Relativamente ao Perfil do Romeiro, de modo global, predomina o gênero feminino e a procedência do estado do Rio Grande do Sul. Com relação à faixa etária, esta não apresentou grandes variações em termos percentuais, do que seria possível inferir que o envolvimento com a Romaria independe da idade, pois dela participam romeiros de todas as faixas etárias, reiterando, assim, a importância que lhe é conferida indistintamente. Também a maior parte dos entrevistados participou mais de dez vezes da Romaria - novamente um indicativo da forte relação dos sujeitos com a Romaria.

No que concerne ao segundo eixo norteador, Manifestações/Destaques sobre Acolhimento/Hospitalidade na Romaria, dos 125 fragmentos de respostas destacados, $66,4 \%$ relacionaram-se a uma síntese avaliativa ou a um juízo de valor. Na seleção e na organização do discurso estaria, pois, a representação enunciativa da aglutinação de significações atribuídas à experiência de acolhimento dos romeiros. Essas expressões-síntese, em sua totalidade, apresentaram uma valência positiva, manifesta em diferentes graus de positividade, os quais foram agrupados em quatro grandes níveis: Satisfatório, Bom, Muito Bom e Ótimo/Excelente. Em linhas gerais, poder-seia dizer que, em relação ao acolhimento na Romaria, as expressões-síntese 
que melhor o definiriam encontram-se nos níveis Muito Bom e Ótimo/ Excelente, denotando que emoções fortemente marcadas pelo grau de positividade estariam impactando a representação mental construída sobre as experiências ali vividas.

Na continuidade da organização/análise dos dados, foram construídas as categorias e as respectivas subcategorias: Relações Sócio-Humanas - Educação, Atendimento e Disposição Receptiva; Impressões Sociocognitivas - Clima Contextual; Planejamento e Organização Socioadministrativa - Estrutura Física, Estrutura de Apoio, Organização Espacial, Organização Geral e Serviços; e Aspectos Religiosos - Templo, Contingente de Fiéis, Palavra dos Representantes da Igreja, Ritos (missa) e Demonstrações de Fé. O maior número de verbalizações registra-se na categoria Planejamento e Organização Socioadministrativa, o que permitiria inferir que, para a maioria dos entrevistados, o acolhimento na Romaria estaria relacionado a aspectos estruturais e de organização. $\mathrm{Na}$ outra ponta encontra-se a categoria Impressões Sociocognitivas, com o menor número de verbalizações. Já a categoria Aspectos Religiosos ocupa a terceira posição, o que, a princípio, mostra uma menor aproximação entre o acolhimento e o universo religioso, mesmo em se tratando de uma Romaria.

No que se refere às subcategorias, considerando, em ordem decrescente, sua representatividade no conjunto de fragmentos de respostas, as cinco subcategorias com maior incidência de respostas são: Disposição Receptiva, Organização Geral, Estrutura de Apoio, Clima Contextual e Atendimento.

Em se tratando da Motivação para a Participação na Romaria, de uma maneira geral, em sua maioria, os entrevistados colocaram em foco aspectos atinentes à própria religião católica, dando destaque ao universo da fé, representado nos elementos: Fé, em si, como Agente Mobilizador; Fé como Objeto de Busca; Fé em Foco Direcional (agradecimento, pedido, homenagem e cumprimento de promessa a Nossa Senhora); Estado de Espírito (buscado na ambiência de fé, religiosidade, espiritualidade) e Religião, em si, como Agente Mobilizador (reza, oração, missa, entre outros aspectos). O tópico Fé: em Foco Direcional é o mais representativo, nele evidenciando-se os subtópicos Fé em Nossa Senhora de Caravaggio e Agradecimento. Esse tópico é seguido por Estado de Espírito: Objeto de Busca. 
Faz-se importante ressaltar outro grupo de fragmentos identificado no conjunto das verbalizações, relacionados a um contexto diferente do contexto da fé. Nesses casos, conhecer, convivência social, exercício físico, por exemplo, seriam as razões/finalidades predominantes da participação na Romaria. Eventuais menções a um elemento de ordem religiosa que se mesclam às verbalizações não se instituem como foco enunciativo. Em comparação à quantidade de fragmentos ligados ao contexto da fé, essas verbalizações elencadas restringem-se a $6 \%$ do total.

Quando perguntados sobre como estava sendo essa sua Experiência de Participação na Romaria, as respostas voltaram-se para cinco tópicos: Aspectos Religiosos, Estado Emocional/Espiritual, Estado Físico, Organização e Outros. Cabe destacar que, em diferentes ocorrências, fragmentos atrelados a mais de um tópico aparecem relacionados a um único sujeito, o que indica estar a experiência sendo marcada simultaneamente por elementos de diferentes ordens.

São os Aspectos Religiosos que se destacam, reiterando a significativa marca da relação de religiosidade na experiência do romeiro. São eles seguidos do tópico Estado Emocional/Espiritual, configurando maior representatividade ainda às marcas de religiosidade, próprias ao contexto de fé em que estão inseridos (com repercussões nas emoções e na vivência de espiritualidade dos romeiros). Paralelamente, repercutem de diferentes formas, mas de modo importante, os tópicos Organização, Estado Físico e Outros. Ressaltese também que referências exclusivas a aspectos organizacionais, sem que o sujeito mencione outros aspectos, bem como ao exercício físico requerido na realização da caminhada, ratificam a importância desses a marcar a experiência de participação da Romaria.

Em síntese, de acordo com os entrevistados, embora haja predominância de algunstópicossobreoutros, comoéocaso dos Aspectos Religiosos, queapresentam o maior número de fragmentos (repetindo-se assim o encontrado quando o foco eram as motivações dos romeiros), poder-se-ia dizer que os aspectos religiosos, o estado emocional/espiritual, o estado físico, a organização do evento e outros aspectos mesclam-se para compor a experiência na Romaria, estabelecendo-se uma inter-relação. Cabe destacar também que a marca dessa experiência para o 
romeiro apresenta-se tonalizada por uma valência predominantemente positiva, ou seja, poder-se-ia dizer que, em uma visão geral, a experiência de participação na Romaria apresenta um grau elevado de positividade.

\section{Nas respostas sobre Destaques que Fariam sobre a Romaria a Eventuais}

Futuros Romeiros, identificaram-se as palavras-chave: Sentir/Vivenciar, Ver, Encontrar, Pedir/Receber/Alcançar/Agradecer, Evento Para... Constata-se uma significativa priorização da experiência religiosa, quer no tocante à fé, aos ritos católicos, às formas de relação do romeiro com Nossa Senhora, quer no que tange à perspectiva de vivência de reflexões, emoções e de um novo estado espiritual - que ali poderia sentir, ver, encontrar. Em seu discurso, os sujeitos projetam para o outro (eventual futuro romeiro) elementos constitutivos de sua fé, de sua própria experiência. Encontram-se também respostas dos entrevistados, as quais encerram em sua maioria recomendações, sugestões, incentivo ou aconselhamento para participação na Romaria.

\section{A VOZ DOS ROMEIROS: UMA SÍNTESE INTERPRETATIVA}

Até o presente momento, a voz dos romeiros foi "ouvida" em fragmentos. Portanto, cabe agora encaminhar para uma reconfiguração dessa voz, no sentido de sintetizá-la interpretativamente. Voltando, novamente, o olhar sobre a organização e a análise dos fragmentos discursivos das respostas às entrevistas sobre relações de hospitalidade na RNSC sob a ótica do romeiro, as categorias e as subcategorias construídas, bem como marcas linguístico-enunciativas identificadas/destacadas, sinalizam, sinteticamente, para uma relação em que o romeiro, desde sua posição de acolhido, entende o acolhimento como aquilo que o acolhedor pode/deve lhe oferecer para que seus desejos sejam acolhidos (no caso, o de vivenciar a experiência religiosa a que ele se propôs). Dito de outra forma: ele se situa como objeto do acolhimento e não como sujeito de acolhimento nessa relação. Vislumbra-se aí uma aproximação com o conceito de hospitalidade, cujo foco recai sobre o bem-receber e sobre as ações que isso implica para o polo do acolhedor - foco esse para o qual, via de regra, convergem abordagens do fenômeno. 
Nesse sentido, poder-se-ia remeter aos tópicos em que foram categorizados os fragmentos nodais das verbalizações dos sujeitos, particularmente Planejamento e Organização Socioadministrativa (com suas subcategorias Estrutura Física, Estrutura de Apoio, Organização Espacial, Organização Geral e Serviços) e Relações Sócio-Humanas (com suas subcategorias Educação, Atendimento e Disposição Receptiva), as quais abrangeram o maior número de fragmentos, indicando que a maioria dos entrevistados associa a hospitalidade na Romaria a aspectos estruturais, organizacionais e interacionais. Com menor representatividade, encontram-se os Aspectos Religiosos e as Impressões Sociocognitivas.

Identifica-se, assim, que tanto os sujeitos que recebem quanto os aspectos estruturais e organizacionais parecem instituir-se como elementos-função, ali concorrendo favoravelmente para a consecução de uma experiência religiosa. Isso sinaliza como o acolhido, numa visão autocentrada, espera que o acolhedor seja em relação a ele, bem como o que o acolhedor deve prever, implementar e assegurar para prover as condições necessárias ao atendimento de seus desejos e de suas expectativas. O acolhimento nas verbalizações se apresenta assim por diferentes falas, sejam elas estruturais, organizacionais ou psicoafetivas, reforçando a compreensão de que as relações de hospitalidade ali não prescindem dos espaços em que elas se verificam. Os espaços instauram uma "linguagem" que vem ratificar a consecução do acolhimento na forma como almejado pelo romeiro. Essas falas encerram ainda o elevado grau de positividade com que, em conformidade com as análises anteriormente realizadas, a maioria dos sujeitos expressa a síntese avaliativa da hospitalidade na Romaria, nela marcando a representação mental construída sobre as experiências ali vividas. Como visto, é significativa a incidência de expressões-síntese que apontam para um nível muito bom, ou mesmo, para a excelência do acolhimento almejado e recebido. Ressalte-se igualmente que não se identificam maiores discrepâncias referentemente a essa valência positiva quando considerados os dados gerais caracterizadores do perfil dos sujeitos (gênero, faixa etária, procedência, número de participações na Romaria, forma de locomoção).

Numa primeira inferência no que diz respeito ao Corpo Coletivo Acolhedor (termo cunhado por Santos, Perazzolo e Pereira, 2012) em que se institui a 
Romaria, as relações de hospitalidade, sob a ótica do romeiro, incidiriam, portanto, sobre os vértices Organismo Gestor e Serviços, respectivamente, aquele afeto à administração e à disponibilização dos recursos para manutenção e desenvolvimento do corpo social e aquele em que se dá a rede de trocas com o acolhido em seus diferentes âmbitos: as mãos do Corpo. Em se tratando, porém, de um modelo concebido sistemicamente, aí estariam imbricamentos com o vértice Capital Cultural, aquele que diz respeito ao conjunto de valores, saberes e respectivos mecanismos de transmissão, bem como ao processo de produção e à socialização dos conhecimentos apropriados pelas comunidades, vértice que abrangeria a Romaria como evento religioso culturalmente instituído e respectivas implicações nas motivações dos romeiros.

De outra parte, nas situações em que isso não se verifica, as respostas, exceção feita àquelas poucas verbalizações que assumem um teor crítico, elas traduzem um processo de relativização por parte dos sujeitos, cujas verbalizações dão a entender a realização de um movimento na direção do outro, ou mesmo, uma disposição para compreender eventuais dificuldades do acolhedor em concretizar o que dele idealmente seria esperado no "cumprimento de suas funções". Entretanto, não obstante esse movimento na direção de entender o outro, o acolhido se mantém em seu lugar, na sua posição de acolhido. Não há referências de como esse se vê num processo dinâmico de mútuo acolhimento (o outro é sempre uma expectativa para mim). Não se infere a abertura a novos saberes numa efetiva relação de acolhimento.

Uma melhor compreensão desse processo poderia ser buscada no conjunto de respostas dos entrevistados sobre suas motivações para participar da Romaria ao Santuário, sobre os destaques dados ao falar sobre sua experiência de participação e sobre aqueles que fariam ao falar acerca do evento religioso a um eventual futuro romeiro. Nos três casos, verifica-se uma convergência explícita e implícita para uma experiência profunda de religiosidade e espiritualidade almejada e/ou vivenciada e/ou renovada, centralizada no universo da fé, esta como agente mobilizador, como objeto de busca ou em foco direcional, quando, particularmente, se expressa numa relação próxima do romeiro com Nossa Senhora de Caravaggio. E é a devoção a Nossa Senhora de Caravaggio que os leva a homenageá-la, a agradecer-lhe, fazer-lhe pedidos, cumprir promessa. 
Outro ponto a ressaltar concerne a Aspectos Religiosos, os quais, dentre os tópicos analíticos dos diferentes eixos temáticos (Motivação, Experiência, Destaques a Eventuais Futuros Romeiros) compreendem os percentuais mais elevados, corroborando estarem os sujeitos centrados no universo da fé e na experiência religiosa e espiritual. Já no tocante à hospitalidade na Romaria, os aspectos religiosos não são mencionados com a mesma frequência, sendo marcados apenas traços específicos de ritos e demonstrações de fé, talvez porque os aspectos religiosos sejam inerentes à prática da Romaria e ao desejo dos romeiros. Observa-se desse modo uma congruência das respostas nos diferentes eixos temáticos, na medida em que concorrem para colocar em evidência o foco principal da motivação e da experiência do romeiro, que é o de realizar um movimento para dentro de si, de interiorização na e com a sua fé, buscando-a, fortalecendo-a e nela se fortalecendo, renovando-a e nela se renovando, "re"conhecendo-a e nela se "re"conhecendo.

Esse movimento na direção de si, de interiorização, seria também o que permitiria compreender, relativamente ao acolhimento, a ausência de sinalizadores discursivos de uma relação recíproca entre os dois polos envolvidos (acolhedor e acolhido), com uma abertura a novos saberes, pela disposição de "ouvir um ao outro", "perguntar um ao outro", "mudar um com o outro". Não se identifica um diálogo que encena um "eu" e um "tu" e que se transforma num discurso aumentado, no qual as "[...] duas vozes se fundem uma na outra em um 'nós" (BESSONE, 2011, p. 1275).

No entanto, esta síntese interpretativa não poderia prescindir de voltar atenção aos sujeitos cujas verbalizações sobre suas motivações recaem preponderantemente sobre um contexto diferente do universo da fé, ainda que representem um pequeno percentual no conjunto dos respondentes. Quando eventual menção a um elemento de ordem religiosa se mescla às verbalizações, ela não se institui como foco enunciativo.

Contrapondo essas motivações ao que os sujeitos revelam sobre sua experiência de participação na Romaria e aos destaques que fariam a eventuais futuros romeiros, distinguem-se dois grandes conjuntos de verbalizações: aquelas que explicitamente não denotam e as que denotam novos saberes ali 
adquiridos. No primeiro caso, encontram-se aqueles cujo deslocamento, por exemplo, teve em sua origem um mero exercitar físico, um fazer companhia, fazer um passeio ou uma simples referência a conhecer. Nas respectivas verbalizações não são expressas aprendizagens transformadoras. No segundo caso, se situam aqueles cujo deslocamento foi motivado "pelo turismo religioso", "mais pra conhecer" (sujeito que se diz não devoto). As respectivas motivações deram lugar a novos saberes. Em ambas as situações, fica bem marcado que vivenciar uma experiência de religiosidade, de espiritualidade, de interiorização não consiste no elemento mobilizador desses sujeitos. Poder-se-ia então denominá-los ou caracterizá-los de romeiros? Ou ainda, conforme referido por um dos sujeitos, poder-se-ia falar em turismo religioso?

Diversas poderiam ser as respostas a essas questões, conforme sejam vinculadas aos conceitos construídos/propostos pelos diferentes estudiosos de turismo, turismo religioso, peregrinações e romarias. Por exemplo, se a fé for tomada como motivação essencial e primordial do turismo religioso (o que caracterizaria o romeiro e o peregrino) (CHIQUIM, s.d.), esses sujeitos não estariam inseridos no turismo religioso. Se o turismo religioso for relacionado à participação em romarias e peregrinações e à utilização da estrutura turística (CHIQUIM, s.d.; KRIEGER, 2007), esses sujeitos poderiam ser considerados turistas religiosos mesmo participando da Romaria a Caravaggio e não sendo motivados primariamente por aspectos/elementos ligados à religiosidade. Já se o turismo religioso for caracterizado pela externalidade do olhar e as peregrinações e as romarias pela internalidade da imersão no sagrado, sem que nisso interfira o critério da utilização da estrutura turística (STEIL, 2003); e se o turismo religioso for definido como a busca de conhecimento de diversos enclaves da manifestação religiosa, aproximando-se de uma forma de turismo cultural, e a peregrinação entendida como viagem de caráter religioso, na qual a motivação prioritária são os rituais e o culto (PASTOR, 2009); esses sujeitos seriam primariamente turistas religiosos e não romeiros.

Por outro lado, se o conceito de turismo religioso for pautado pelo entendimento de turismo como fenômeno motivado pelo impulso/vontade de conhecer na sua forma mais intrínseca de busca do novo, do prazer em outro lugar, cujo objeto original não pode ser identificado (PERAZZOLO; 
SANTOS; PEREIRA, 2013a; 2013b) - conceito de referência neste trabalho -, então o turismo religioso também encerraria, na relação empírica, a busca pelo conhecer, pelo novo, na externalidade do olhar, potencializada por relações genuínas de acolhimento (troca de posições entre acolhedor e acolhido) geradoras de novos saberes, e o elemento religioso se instituiria como objeto desse conhecer: um local religioso ou considerado sagrado, eventos/práticas religiosos, uma religião, manifestações/obras artístico-cultural-religiosas, entre outras possibilidades.

A partir desse olhar, tais sujeitos sobre os quais se fizeram as perguntas acima (cuja motivação não estava primariamente na vivência de uma experiência de religiosidade/espiritualidade), poderiam ser considerados turistas religiosos, uma vez que abertos a novos saberes, com olhar voltado à externalidade, diferentemente do identificado em relação aos demais entrevistados, voltados à internalidade - o que não impediria que algum elemento ou alguma situação no evento (incluídas relações de acolhimento) pudessem despertá-los para uma experiência de outra ordem, como a de religiosidade/espiritualidade.

Contudo, cabe destacar que, independentemente de percursos teóricos que envolvam o universo conceitual de turismo religioso, turista e peregrino/ romeiro se encontram no que é profundo no humano: sua condição de não se bastar a si próprio.

\section{NA DIREÇÃO DE CONSIDERAÇÕES FINAIS}

No momento em que se intenta ir na direção de considerações finais, cabe voltar ao início da caminhada, quando se delineou o percurso que seria traçado no sentido de trazer a voz do romeiro em relação à hospitalidade na Romaria de Caravaggio, bem como propiciar uma reflexão sobre a denominação de turismo religioso à Romaria; mais ainda, quando se perspectivou eventual possibilidade de o trabalho vir a aportar novos subsídios para realizar uma releitura do projeto desenvolvido pelas autoras em 2010. Findo o percurso, os relatos, as análises e as interpretações realizadas permitem identificar a consecução dos objetivos propostos, bem como algumas contribuições de cunho científico e social que dele se poderia derivar. 
Primeiramente, ao amplo leque conceitual envolvendo espiritualidade, religiosidade, turismo, turismo religioso, hospitalidade, peregrinações, romarias para o qual já apontavam os estudos que têm sido desenvolvidos, veio somar-se um novo olhar sob as lentes de um marco teórico de base psicossociológica, o qual remeteu a outras possibilidades interpretativas das relações de hospitalidade em romarias. A par disso, o trabalho, ao alicerçar-se nas entrevistas efetivadas, trouxe evidências empíricas, metodologicamente construídas, ao processo argumentativo, indo além de uma racionalidade elaborada apenas em âmbito conceitual.

Foi também a partir dos dados analisados e convertidos em evidências empíricas, que se propôs uma compreensão de turismo religioso na qual não estariam incluídas as romarias e as peregrinações quando essas não fossem objeto do conhecer, configurado na sua externalidade. Não se veja aí qualquer postura de rigidez conceitual, em tendo como pressuposto que os conhecimentos científicos produzidos são apenas verdades provisórias. A proposição aqui construída para turismo religioso deve, pois, ser considerada somente em relação ao conceito de turismo que, nesta pesquisa, principalmente balizou as reflexões.

Por outro lado, ainda referente a possibilidades de contribuição desta investigação para eventual releitura do projeto desenvolvido na Graduação em Turismo (2010), quando se deu voz aos promotores/organizadores da RNSC e a alguns prestadores de serviços localizados no entorno do Santuário (sujeitos primariamente acolhedores), pode-se dizer, em linhas gerais, que se identificou uma consonância entre os dados obtidos em ambas as pesquisas.

Sob a ótica dos acolhedores, a hospitalidade se encerra no atender bem, visando propiciar ao romeiro (sujeito primariamente acolhido), da melhor forma possível, o "bem-estar" e o "sentir-se bem", o que, em suas manifestações, é marcado, de um lado, pela consciência, sobretudo, das limitações de estrutura e, consequentemente, pela necessária busca de melhorias; de outro, pela atenuação de eventuais dificuldades, contando com a compreensão do romeiro imerso em sua experiência religiosa.

A hospitalidade é expressa no sentido de oferecer aquilo de que o acolhido supostamente necessitaria, ou seja, condições tidas como favoráveis à 
vivência plena da experiência religiosa e ao fortalecimento do "eu religioso". Assim, a disposição do acolhedor para acolher consistiria no acolhimento das demandas do acolhido, as quais ele, como acolhedor, pressupõe. Nas respostas, não se identificou referência à busca de conhecimento da voz do romeiro, ao qual, inclusive, são feitas menções sempre de forma despersonalizada. Não há manifestações de busca de aprender com o outro (o romeiro), o que remete a uma perspectiva autocentrada de acolhimento.

Por sua vez, quando examinadas as respostas dos romeiros (acolhidos), às quais se fez alusão nas análises precedentes, seu entendimento de acolhimento está centrado no polo do acolhedor: ele espera que lhe sejam proporcionadas as condições que the permitam vivenciar a experiência de religiosidade e espiritualidade pretendida, incluídas melhorias em diferentes âmbitos. É pela priorização da dimensão religiosa que são relevados eventuais problemas que possam ocorrer, no entanto, isso não altera o que almeja receber.

Revisitando, pois, a pesquisa de 2010 e articulando-a com o presente estudo, pode-se depreender haver, na Romaria, um acolhimento tácito, de comunicação prévia, em que acolhedor e acolhido esperam sejam mantidas, na sua essência, as formas de receber e ser recebido. Há entre acolhedor e acolhido uma troca reiterativa: nem um, nem outro trazem perguntas. $O$ acolhimento tem uma função sustentadora, não de mudança. Portanto, o Corpo Coletivo que acolhe o romeiro e que se reinstaura a cada ano mantémse na sua essência, porque esta repousa no religioso. A isso, contudo, não se pode atribuir qualquer conotação negativa. Esse silêncio relacional estaria expressando mútuo respeito num contexto de primazia religiosa.

Todavia, ao mesmo tempo em que se destacam contribuições, há também que se trazer algumas restrições ou limitações do trabalho já identificadas, como lacunas decorrentes de não terem sido ampliados e/ou aprofundados estudos que têm como objeto outras romarias, tais como: no Brasil, Aparecida do Norte, Bom Jesus da Lapa, Juazeiro do Norte, Nossa Senhora de Nazaré, Divino Pai Eterno; no exterior, Fátima, Lourdes, Guadalupe. Isso não possibilitou a realização de estudos comparativos, que poderiam trazer novos horizontes e desdobramentos interpretativos às relações de hospitalidade na Romaria 
ao Santuário de Nossa Senhora de Caravaggio e em outras romarias, às peregrinações e ao turismo religioso.

Porém, apesar desses recortes, as incursões conceituais e pragmáticas realizadas ao longo do processo de investigação já permitiram que se pusessem a dialogar diferentes perspectivas teóricas, diálogo do qual não poderiam prescindir aqueles a quem cabe pensar o planejamento, a organização e a implementação de ações ligadas a turismo religioso, a peregrinações e romarias, particularmente no que se refere ao acolhimento.

\section{REFERÊNCIAS}

ABUMANSSUR, Edin Sued. Religião e turismo: notas sobre as deambulações religiosas. In: Turismo religioso: ensaios antropológicos sobre religião e turismo. Campinas: Papirus, 2003 (Coleção Turismo).

BAKHTIN, Mikhail. Estética da criação verbal. 2. ed. São Paulo: Martins Fontes, 1997. Disponível em: <http://www.4shared.com/file/131261767/5c23af6a/LIVRO_BAKHTIN_ Estetica_Criacao_Verbal.html>. Acesso em: 17 fev. 2012.

BALBINOT, Gustavo. Espiritualidade X Religião. Ruah, Porto Alegre, n. 55, p. 18, 2011. Disponível em: <http://www.pucrs.br/pastoral/ruah/pdf/ruah201101.pdf\#page=18>. Acesso em: 05 jan. 2012.

BAPTISTA, Isabel. Lugares de hospitalidade. In: DIAS, Celia Maria de Moraes (Org.). Hospitalidade: Reflexões e Perspectivas. Barueri: Manole, 2002.

BARDIN, Laurence. Análise de Conteúdo. Traduzido por: Luís Antero Reto e Augusto Pinheiro. Lisboa: Edições 70, 2000.

BENI, Mário Carlos. Análise estrutural do turismo. 12. ed. rev. e atualiz. São Paulo: Senac São Paulo, 2007.

BESSONE, M. Do eu ao nós. In: MONTANDON, Alain (Dir.). O livro da hospitalidade: acolhida do estrangeiro na história e nas culturas.Tradução de M. Bagno e L. Zylberlicht. São Paulo: Senac, 2011.

BETTEGA, Jaime João. A experiência da espiritualidade e sua relação com o desempenho dos trabalhadores em uma indústria metalúrgica do segmento eletroeletrônico. 2009, 110 f. Dissertação (Mestrado) - Universidade de Caxias do Sul, Programa de Pós-Graduação em Administração, 2009. Disponível em: <https://ucsvirtual.ucs.br/tedeposgraduacao/ 
ISSN: 1983-7151

tde_busca/arquivo.php?codArquivo=291>. Acesso em 29 out. 2011.

BOFF, Leonardo. Espiritualidade: um caminho de transformação. Rio de Janeiro: Sextante, 2006.

BRUSTOLIN, Leomar Antônio. Santuário: caminhos de contemplação da beleza de Deus. Teocomunicação, Porto Alegre, v. 37, n. 156, p. 231-239, 2007. Disponível em: <http:// revistaseletronicas.pucrs.br/ojs/index.php/teo/article/viewFile/2704/2055>. Acesso em: 05 jan. 2012.

BUENO, Marielys Siqueira. Introdução. In: DENCKER, Ada de Freitas Maneti; (Orgs.). Hospitalidade: Cenários e Oportunidades. São Paulo: Pioneira Thomson Learning, 2003.

CAMARGO, Luiz Octávio de Lima. Turismo, hotelaria e hospitalidade. In: DIAS, Celia Maria de Moraes (Org.). Hospitalidade: Reflexões e Perspectivas. Barueri: Manole, 2002.

CARNEIRO, Sandra Maria Corrêa de Sá. Novas peregrinações brasileiras e suas interfaces com o turismo. Ciências Sociais e Religião, Porto Alegre, v. 6, n. 6, 2004. Disponível em: <http://seer.ufrgs.br/index.php/CienciasSociaiseReligiao/article/viewArticle/2267>. Acesso em: 29 abr. 2010.

CHIQUIM, Carlos Alberto. Turismo religioso sustentável. Guia Turismo religioso. Curitiba: Instituto Gaudium de Proteção a Vida, s.d.

CNBB, Conferência Nacional dos Bispos do Brasil. Pastoral do Turismo: desafios e perspectivas. Brasília: Edições CNBB, 2009.

CORDEIRO, Maria Paula Jacinto. O vivido, o recorrente e o construído: tramas de significação em contexto de romarias. In: Congresso Luso Afro Brasileiro de Ciências Sociais, 11, 2011, Salvador. Anais do XI Congresso Luso Afro Brasileiro de Ciências Sociais. Salvador: [s.ed.], 2011, p. 1-13. Disponível em: <http://www.xiconlab.eventos. dype.com.br/resources/anais/3/1308348952_ARQUIVO_Artigocompleto-CONLABGT17MariaPaulaJacintoCordeiro.pdf>. Acesso em: 09 jan. 2012.

CRISPIM, Lizete de Oliveira. Evento religioso e lazer: vivência acadêmica na peregrinação de Madre Paulina. In: Encontro Nacional de Recreação e Lazer, 14, 2002, Santa Cruz do Sul/RS. Anais do 14 $^{\circ}$ Encontro Nacional de Recreação e Lazer. Santa Cruz do Sul/RS: Universidade de Santa Cruz do Sul, 2002. Disponível em: <http://www.redcreacion.org/ documentos/enarel14/Mt_ppp03.html>. Acesso em: 09 jan. 2012.

CRUZ, Rita de Cássia Ariza da. Hospitalidade turística e fenômeno urbano no Brasil: considerações gerais. In: DIAS, Celia Maria de Moraes (Org.). Hospitalidade: Reflexões e Perspectivas. Barueri: Manole, 2002. 
DE FIORES, Stefano; MEO, Salvatore (Orgs.). Dicionário de Mariologia. Traduzido por: Álvaro A. Cunha, Honório Dalbosco, Isabel F. L. Ferreira. São Paulo: Paulus, 1995.

DENCKER, Ada de Freitas Maneti. A Abordagem Científica em Hospitalidade. In: BUENO, Marielys Siqueira (Orgs.). Hospitalidade: Cenários e Oportunidades. São Paulo: Pioneira Thomson Learning, 2003.

DIAS, Reinaldo; SILVEIRA, Emerson José da. Turismo religioso: ensaios e reflexões. Campinas: Alínea, 2003.

DUARTE, Ana Helena da S. Delfino. Romarias: experiência de fé e circularidade cultural. In: Encontro Regional de História, 20, 2010, Franca, Anais do XX Encontro Regional de História. Franca: [s.ed.], 2010. Disponível em: <http://www.anpuhsp.org.br/downloads/ CD\%20XX\%20Encontro/ PDF/Autores\%20e\%20Artigos/Ana\%20Helena\%20da\%20S. \%20 Delfino\%20Duarte.pdf>. Acesso em: 09 jan. 2012.

DURKHEIM, Émile. As formas elementares da vida religiosa: o sistema totêmico na Austrália. Traduzido por: Paulo Neves. São Paulo: Martins Fontes, 1996 (Coleção Tópicos). Tradução de: Les formes elementares de la vie religieuse.

ELIADE, Mircea. Origens: história e sentido na religião. Traduzido por: Teresa Louro Perez. Lisboa: Edições 70, 1989. Tradução de: The Quest.

ELIADE, Mircea. O sagrado e o profano: a essência das religiões. Traduzido por: Rogério Fernandes. São Paulo: Martins Fontes, 1992. Tradução de Le sacré et le profane.

ELIADE, Mircea. Tratado de história das religiões. Traduzido por: Fernando Tomaz e Natália Nunes. São Paulo: Martins Fontes, 1998. Tradução de: Traité d'histoire des religions.

GIDRA, Gilberto; DIAS, Celia Maria de Moraes. Hospitalidade: da simplicidade à complexidade. In: DENCKER, Ada de Freitas Maneti (Org.). Planejamento e Gestão em Turismo e Hospitalidade. São Paulo: Pioneira Thomson Learning, 2004.

GOTMAN, Anne. Le sens de I’hospitalité. Paris: Presses Universitaires de France, 2001.

KRIEGER, Dom Murilo S. R. Pastoral do Turismo: um desafio para a Igreja. Florianópolis: [s.ed.], 2007. Documento pessoal. Mensagem recebida por <dom.murilo@arquifln.org.br> em 28 dez. 2011.

MANOEL, Ivan Ap. História, religião e religiosidade. Revista Brasileira de História das Religiões, Maringá, n. 1, p. 18-33, 2008. Disponível em: < http://www.dhi.uem.br/gtreligiao/ pdf/03\%20Ivan\%20Ap.\%20Manoel.pdf>. Acesso em: 06 set. 2011. 
NOLAN, M. L.; NOLAN, S. Christian pilgrimage in modern western Europe. Chapel Hill: The University of North Caroline Press, 1989.

OLIVEIRA, Christian Dennys Monteiro de. Turismo religioso. São Paulo: Aleph, 2004 (Coleção $A B C$ do Turismo).

PASTOR, Vicente Elías. Turismo religioso. In: Otras formas de turismo. México: Trillas, 2009.

PERAZZOLO, Olga Araújo; SANTOS, Marcia Maria Cappellano dos; PEREIRA, Siloe. Dimensión relacional de la acogida. Estudios y perspectivas em turismo, Buenos Aires, v. 22, n. 1, jan., 2013, p. 138-153. Disponível em: <http://www.estudiosenturismo.com.ar/PDF/V22/N01/ v22n1a08.doc.pdf >. Acesso em: 22 fev. 2013.

. O acolhimento - ou hospitalidade turística - como interface possível entre o universal e o local no contexto da mundialização. Revista de turismo y patrimônio cultural - Pasos, La Laguna, v. 11, n. 1, jan., 2013, p. 45-55. Disponível em: <http://www.pasosonline.org/ Publicados/11113/PS0113_04.pdf>. Acesso em: 22 fev. 2013.

RIBEIRO, Heloisa. Andar com fé e o sentido do chegar. Caderno Virtual de Turismo, Rio de Janeiro, v. 3, n. 1, 2003. Disponível em: <http://www.ivt.coppe.ufrj.br/caderno/ojs/viewarticle. php?id=25\&layout=abstract $>$. Acesso em: 29 abr. 2010.

ROMARIA registra público de 230 mil. O Farroupilha, Farroupilha, 01 jun. 2012, Expressões/ Evento, p.5.

SALGUEIRO, Jennifer Braathen; GOLDIM, José Roberto. As múltiplas interfaces da bioética com a religião e a espiritualidade. In: GOLDIM, José Roberto (Org.). Bioética e espiritualidade. Porto Alegre: EDIPUCRS, 2007.

SANTOS, Marcia Maria Cappellano dos; PERAZZOLO, Olga Araújo; PEREIRA, Siloe. Hospitalidade numa perspectiva coletiva: o corpo coletivo acolhedor. Revista brasileira de pesquisa em turismo, São Paulo, v. 6, n. 1, jan.-abr., 2012, p. 3-15. Disponível em: <http:// www.rbtur.org.br/ojs/index.php/rbtur/article/view/484/503>. Acesso em: 23 ago. 2012.

STEIL, Carlos Alberto. Peregrinação, romaria e turismo religioso: raízes etimológicas e interpretações antropológicas. In: ABUMANSSUR, Edin Sued. Turismo religioso: ensaios antropológicos sobre religião e turismo. Campinas: Papirus, 2003 (Coleção Turismo). 